\title{
Do diatoms arrest embryonic development in copepods?
}

\author{
S. A. Poulet ${ }^{1}$, A. Ianora ${ }^{2}$, A. Miralto ${ }^{2}$, L. Meijer ${ }^{1}$ \\ ${ }^{1}$ Observatoire Océanologique, CNRS \& Université Paris VI, Place Georges Teissier, F-29682 Roscoff, France \\ ${ }^{2}$ Stazione Zoologica 'A. Dohrn', Villa Comunale, I-80121 Napoli, Italy
}

\begin{abstract}
Evidence is presented on the harmful impact of a diatom (Thalassiosira rotula) on the reproductive biology of the copepod Calanus helgolandicus. When adult females were fed the diatom, both total egg production and hatching success were significantly lower than with the dinoflagellate Prorocentrum minimum. Embryonic development in the copepod was arrested when eggs were exposed to diatom but not dinoflagellate extracts from these same species of phytoplankton. Depending on the age of the eggs before exposure, cell division was blocked either prior to fusion of male and female pronuclei, or during mitosis. Embryos underwent strikingly abnormal development. The structural anomalies included a dark brown, opaque outer membrane, globular cytoplasm, blockage of pronuclei, or dispersed chromatin scattered in the egg matrix of non-hatched eggs either spawned by naturally occurring females, spawned by females fed with diatoms, or in embryos incubated in diatom. extracts. The production by several species of diatoms of inhibitory compound(s) detrimental to the development and survival of their principal grazers may have major implications on secondary production and on the flow of energy in the marine food web.
\end{abstract}

KEY WORDS: Copepod - Diatom · Inhibition · Development

\section{INTRODUCTION}

Blooms of phytoplankton, generally dinoflagellates or flagellates (Smayda 1991), are known to induce mass kills of fish and shellfish due to anoxia caused by bacterial breakdown of the bloom, and to their potent toxins which cause diarrheic shellfish poisoning (DSP), neurotoxic shellfish poisoning (NSP) and paralytic shellfish poisoning (PSP) in man. Several species of dinoflagellates and flagellates also adversely affect copepod feeding, egg production, and survival (Huntley et al. 1987, Verity \& Smayda 1989). Diatoms (Bacillariophyceae), another major component of the phytoplankton, were rarely reported as toxic to marine organisms until the identification of high concentrations of domoic acid in Nitzschia pungens f. multiseries by Douglas \& Bates (1992). Diatoms may, however, have other harmful modes of action to zooplankton (e.g. inhibition of feeding and survival of adults) with harmful consequences for the marine food web (e.g. growth inhibitor in zooplankton, chemical interactions among phytoplankton: DeMott et al. 1991, Imada et al.
1991, Kirk \& Gilbert 1992). Inhibition by diatoms of egg production and hatching rates in Temora stylifera has recently been documented (Ianora \& Poulet 1993, Ianora et al. 1994).

Copepod fecundity depends on the abundance, chemical composition and digestibility of food items (Kleppel et al. 1991), as well as environmental factors such as temperature and nutrient recycling (Kiørboe et al. 1988), or remating (Ianora et al. 1989). Discrepancies in the reproductive responses of copepods fed either diatom or dinoflagellate diets have been attributed to differences between these 2 groups of phytoplankton, such as an absence or presence of cell wall silica, shape and size of cells, palatability or concentration of nutrients per unit cell volume (see Ianora $\&$ Poulet 1993). A question that has rarely been addressed is what fraction of the total egg production is viable. Answering this question is essential to understanding copepod population dynamics and also the processes governing their recruitment in the sea.

Some of our recent findings showed that successions of low and high egg viability in wild Temora stylifera 
females coincided with periods of high and low diatom densities, respectively (Scotto di Carlo et al. 1985, Ianora \& Poulet 1993). Furthermore, Ianora et al. (unpubl.) have demonstrated that 3 of 4 diatom diets (Thalassiosira rotula, Chaetoceros curvisetum, Phaeodactylum tricornutum and Skeletonema costatum), given at saturation levels $\left(10^{4}\right.$ to $\left.10^{6} \mathrm{cells} \mathrm{ml}^{-1}\right)$ induced lower hatching rates, averaging between 20 and $40 \%$ of total egg production, the exception being $S$. costatum $(78 \%)$. This latter diatom, however, turned out to be a very poor food item for $T$. stylifera since females maintained on this diet produced eggs for only 3 to $4 \mathrm{~d}$ after which they either became sterile or died (Ianora \& Poulet 1993, Ianora et al. unpubl.). In contrast, with 2 non-diatom diets (Prorocentrum minumum and Isochrysis galbana) provided ad libitum, more than $60 \%$ of the eggs produced were viable.

These results suggest that the relative nutritional value of several diatom species negatively affects either total egg production or embryonic development in Temora stylifera. A deficiency of some essential nutrient in the diet could explain the low viability of eggs observed under both in situ and laboratory food conditions characterized by high diatom concentrations (Ianora \& Poulet 1993), or alternatively the presence of inhibitory compound(s) in diatoms that are detrimental to embryonic development and lead to low hatching rates.

\section{MATERIALS AND METHODS}

Five replicate feeding experiments were conducted by incubating 5 batches of 5 Calanus helgolandicus females each, at $15^{\circ} \mathrm{C}$ in $200 \mathrm{ml}$ crystallizing dishes containing $0.22 \mu \mathrm{m}$ filtered sea water, from samples collected offshore of Roscoff (France) in July and September 1993. Containers were enriched with $20 \mathrm{ml}$ of either Thalassiosira rotula (THA; concentration in dish: $10^{3}$ to $10^{5}$ cells $\mathrm{ml}^{-1}$ ) or Prorocentrum minimum (PRO; concentration in dish: $4 \times 10^{3}$ to $1 \times 10^{4}$ cells $\mathrm{ml}^{-1}$ ) cultures, resuspended by stirring 5 times a day. Egg production was recorded daily for 1 to $3 \mathrm{wk}$, by counting all eggs spawned in each container. Each batch of eggs was transfered to dishes containing $400 \mathrm{ml}$ filtered sea water, and incubated for $24 \mathrm{~h}$ at $15 \pm 1^{\circ} \mathrm{C}$, in order to record hatching rate at the end of the incubation period, following a procedure similar to those of lanora \& Poulet (1993) and M. Laabir, S. A. Poulet \& A. Ianora (unpubl.).

Newly spawned (5 to $10 \mathrm{~min}$ old) and older eggs ( 1 to $3 \mathrm{~h}$ old) from wild females were collected and incubated for 12 to $24 \mathrm{~h}$ at $15^{\circ} \mathrm{C}$ in crystallizing dishes containing natural sea water. These were exposed to THA and PRO extracts prepared by centrifuging precounted non-axenic cultures in the exponential phase of growth for $10 \mathrm{~min}$ at $10000 \mathrm{rpm}\left(6000 \times g_{\text {i }}\right.$ Sorvall SS34 centrifuge at $4^{\circ} \mathrm{C}$ ). The pelleted phytoplankton were then homogenized and sonicated 3 times with a Branson sonifer. The homogenate was re-centrifuged at $14000 \mathrm{rpm}(10000 \times \mathrm{g})$ for $10 \mathrm{~min}$ at $4^{\circ} \mathrm{C}$ and the supernatant was then either used immediately or frozen at $-20^{\circ} \mathrm{C}$.

Batches of 20 to 50 eggs were exposed for 1 to $3 \mathrm{~h}$ to $1 \mathrm{ml}$ of extract which was diluted to obtain final culture concentrations equivalent to $14 \times 10^{3}$ to $15 \times 10^{7}$ cells $\mathrm{ml}^{-1}$. Embryonic development was observed microscopically, and photographs (Kodak film 400 ASA) were taken in bright field Nomarsky and fluorescent light, for batches of 12 to 30 eggs initially dyed for $10 \mathrm{~min}$ with $80 \mu \mathrm{l}$ Hoechst 33342 (specific for DNA; SIGMA), or for 2 min with $100 \mu$ l of Trypan blue (specific for DNA in dead cells; SIGMA) solutions in filtered sea water. Early developmental stages in copepods (first cleavage and segmentation cavity: CS stage, terminology from Marshall \& Orr 1972) were used as criteria to follow development, instead of hatching. Longer exposure ( 24 to $72 \mathrm{~h}$ ) to the most concentrated extracts required to reach hatching created artefacts resulting from anoxia.

The effect of diatom extracts on the embryonic development of the sea urchin Sphaerechinus granularis was also examined. Eggs were fertilized following the technique of Meijer et al. (1991). Newly fertilized eggs were placed in $100 \mu$ filtered sea water with increasing volumes ( 0 to $900 \mu \mathrm{l}$ ) of extract at a constant temperature of $19^{\circ} \mathrm{C}$. Sea urchin zygotes were used as a bioassay since they are routinely used for a rapid screening of inhibition of cell division or cell activation during toxicity tests (see Pesando et al. 1990). They were used in our experiments to show that inhibition of embryonic development by diatoms is not limited to Calanus helgolandicus.

Statistical tests ( $t$-test, Kolmogorov-Smirnov test) were performed according to Siegel (1956) and Scherrer (1984)

Cultures used for extracts were checked on 2 occasions by filtration onto $0.2 \mu \mathrm{m}$ Nuclepore filters and observations with a scanning electron microscope. On 2 other occasions, bacterial levels were also checked by streaking algae onto tripticase soy agar plates and incubating these at $30^{\circ} \mathrm{C}$ for $72 \mathrm{~h}$. The bacterial levels were constantly low $\left(10^{3}\right.$ to $\left.10^{4} \mathrm{ml}^{-1}\right)$ in all cultures provided to copepods or used to prepare extracts.

\section{RESULTS}

From January to December 1993 (Laabir et al. unpubl.), annual mean estimates and standard deviations of in situ fecundity and egg viability of naturally 
Fig. 1. Calanus helgolandicus. Mean daily fecundity $(\bullet)$ and hatching success $(0)$ with standard deviations (bars) for females fed either a dinoflagellate (Prorocentrum minimum) or diatom (Thalsassiosira rotula) diet. + : death of females. Results are means of 5 replicate experiments for each diet
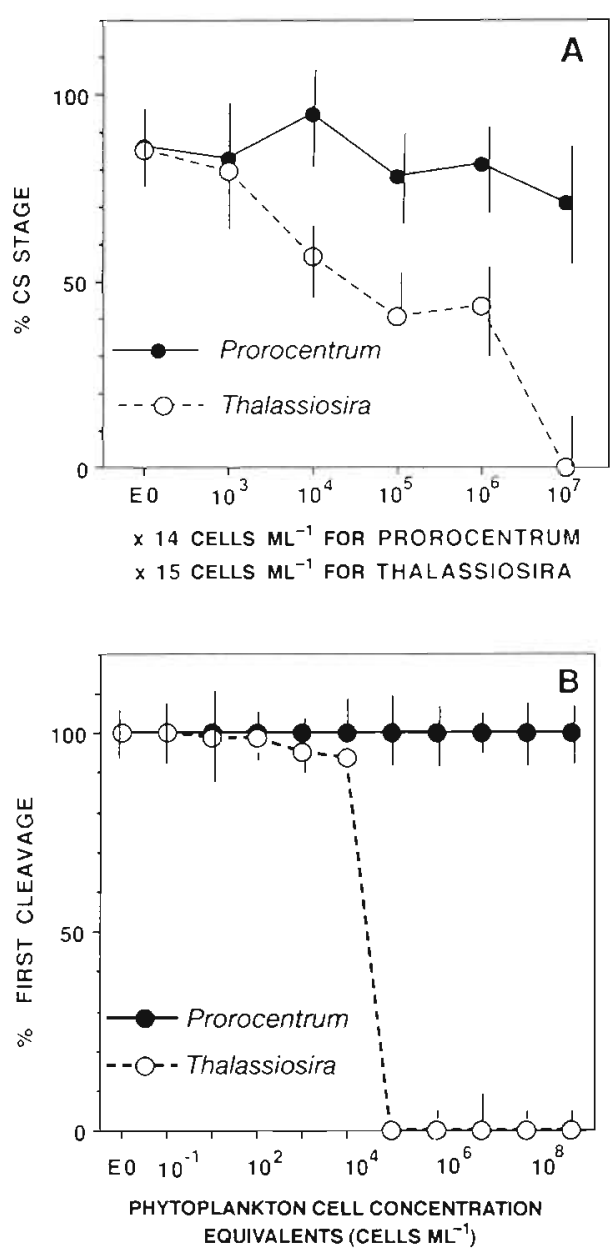

Fig. 2. (A) Calanus helgolandicus. Dilution experiments (in triplicate) with copepods showing means and standard deviations (bars) of \% eggs that develop to the CS stage, with diatom (Thalassiosira rotula) and dinoflagellate (Prorocentrum minimum) extracts, or with control filtered sea water (E0). (B) Sphaerechinus granularis. Dilution experiments (in duplicate) with sea urchin eggs. Inhibition of embryonic development occurred with $T$. rotula extracts at concentrations equal to or higher than $10^{3}$ cells $\mathrm{ml}^{-1}$ Development was $100 \%$ in control filtered sea water (E0) and in the presence of the dinoflagellate extracts
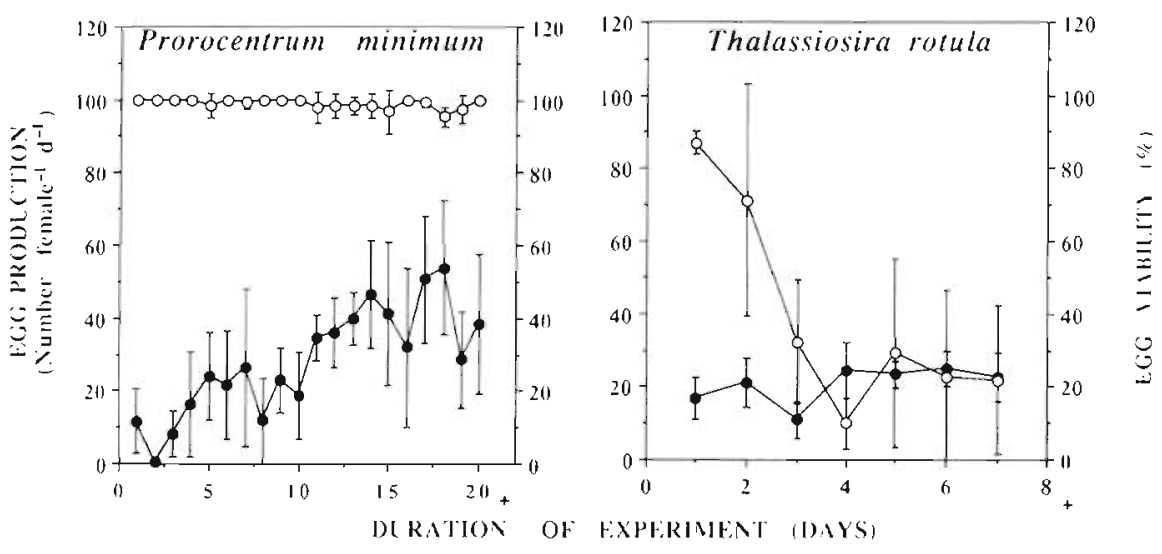

occurring Calanus helgolandicus females were $18 \pm 10$ eggs female $e^{-1} \mathrm{~d}^{-1}$ and $70 \pm 20 \%$ hatching success, respectively. At times, egg mortality was severe with values as high as $60 \%$ of total egg production.

The effect of food on hatching was investigated for females fed either a dinoflagellate (PRO) or diatom (THA) diet for 8 to $20 \mathrm{~d}$. Fig. 1 shows that females had significantly different reproductive responses $(p=$ 0.001 ; $t$-test) depending on the diet. With PRO, egg viability was 95 to $100 \%$ and remained extremely stable throughout the $20 \mathrm{~d}$ period of investigation. Fecundity was very low at the beginning of the experiment, but increased steadily with time, reaching up to 55 eggs $\mathrm{d}^{-1}$ after $18 \mathrm{~d}$. With THA, egg production was much lower and remained stable with time. Egg viability diminished sharply from 80 to $30 \%$ after the first $3 \mathrm{~d}$ and fluctuated between 15 and $30 \%$ until death (from unidentified causes) of the females.

Embryonic development was artificially inhibited using diatom extracts. The results obtained by exposing newly spawned eggs to increasing concentrations of THA and PRO extracts were significantly different $(p=0.001 ;$ Kolmogorov-Smirnov test $)$ and are shown in Fig. 2A. With PRO extracts and control filtered sea water, more than $75 \%$ of the eggs developed normally to the CS stage at all dilutions tested. With THA extracts, egg development was $50 \%$ blocked prior to the CS stage at concentrations higher than $10^{4}$ cells $\mathrm{ml}^{-1}$ and was $100 \%$ blocked at $10^{7}$ cells $\mathrm{ml}^{-1}$. Eggs incubated with these concentrated diatom extracts for 1 and $3 \mathrm{~h}$, rinsed and left in sea water, showed irreversible inhibition. Similar results were obtained with sea urchin eggs (Fig. 2B). Inhibition of mitosis occurred at the first cleavage, as in copepods, but with the THA extracts at a cell density higher than $10^{3}$ cells $\mathrm{ml}^{-1}$. Similar extracts of PRO or culture media from both phytoplankton species $\left(10^{6}\right.$ to $10^{7}$ cells $\left.\mathrm{ml}^{-1}\right)$ filtered through GF/F filters had no effect on cell division of sea urchin zygotes.

The relationship between age of eggs at the time of exposure to extracts and the type of inhibitory 

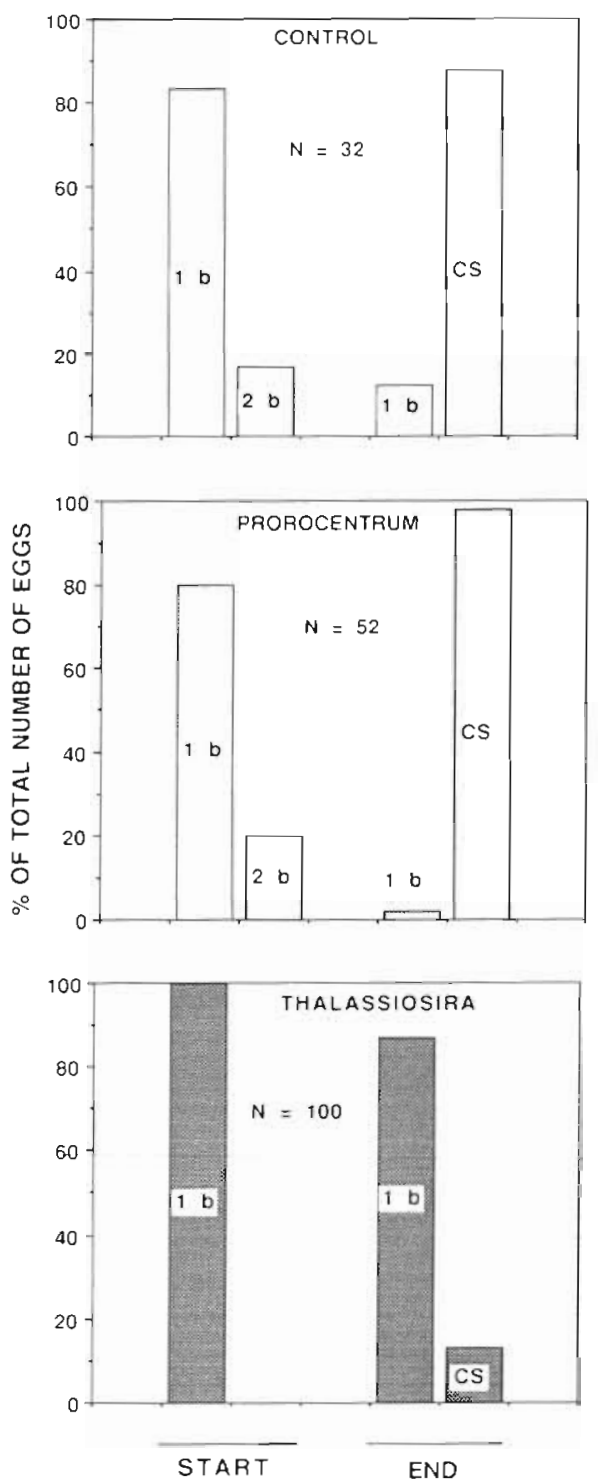

Fig. 3. Calanus helgolandicus. Comparison of different treatments on embryonic development. Development is blocked at the first blastomere stage $(1 \mathrm{~b}=1$ blastomere; $2 \mathrm{~b}=2$ blastomeres) in eggs exposed to diatom extracts (Thalassiosira rotula, at concentrations equivalent to $10^{5}$ cells $\mathrm{ml}^{-1}$ J. Eggs undergo normal development to the $\mathrm{CS}$ stage in non-diatom extracts (Prorocentrum minimum, at concentrations equivalent to $10^{5}$ cells $\mathrm{ml}^{-1}$ ) and in control filtered sea water These experiments were triplicated; data correspond to values of 1 representative experiment. $N$ : total number of eggs observed in each case. Lag time between start and end of incubations was 1 to $3 \mathrm{~h}$

response was examined. Newly spawned eggs (i.e. before fusion of pronuclei) exposed to THA extracts at concentrations equivalent to $10^{5}$ cells $\mathrm{ml}^{-1}$ were blocked at the 1 blastomere (1b) stage (Fig. 3). Eggs underwent normal development to the CS stage in PRO extracts at concentrations equivalent to THA extracts and in control filtered sea water (Fig. 3). Older eggs (i.e. 25 to $40 \mathrm{~min}$ after spawning, at $15^{\circ} \mathrm{C}$ ) in which nuclear fusion had occurred or those that were at the $4 \mathrm{~b}$ or $8 \mathrm{~b}$ stage before addition of THA extracts developed abnormally and never beyond the blastula stage.

Newly spawned eggs in control filtered sea water with a uniform cytoplasm and symmetrical, compact male and female pronuclei are shown in Fig. $4 \mathrm{~A}, \mathrm{~B}$
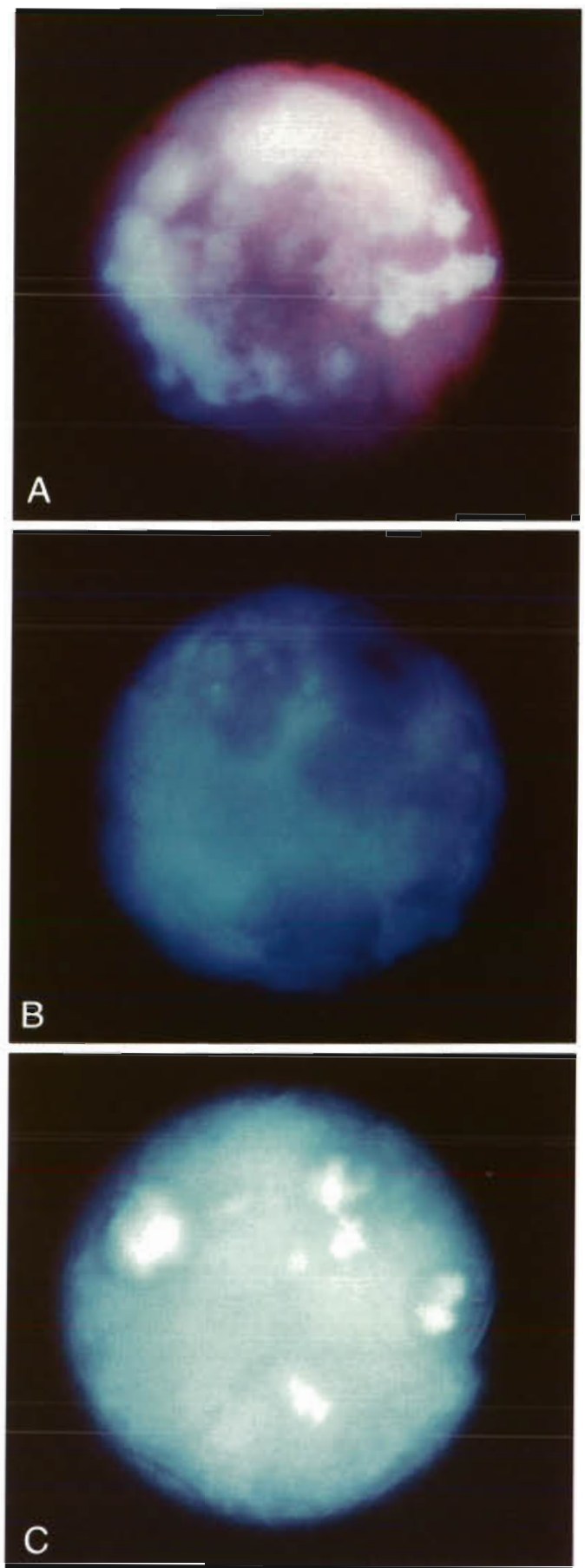
Fig. 4 (right). Calanus helgolandicus. Light microscope photographs of eggs (150 to $170 \mu \mathrm{m}$ diameter). (A, C, E, G) In bright field-Nomarsky; (B, D, F, H) with fluorescent light. Same batch of eggs, in $(\mathrm{A}, \mathrm{B}, \mathrm{E}, \mathrm{F})$ control filtered sea water or $(C, D, G, H)$ exposed for 1 to 2 h to diatom extracts (Thalassiosira rotula at a concentration of $10^{6}$ cells $\mathrm{ml}^{-1}$ ), were dyed with Hoechst 33342. (A, B) Newly spawned eggs, at $1 \mathrm{~b}$ stage, or $(E, F)$ older embryos at the CS stage present normal structures in controls. In extracts, they showed abnormal develop ment, characterized by globular structures (C, G) and dispersed chromatin scattered in the egg matrix (D, H)

Fig. 5 (left). Calanus helgolandicus. Fluorescent light images of older eggs at the CS stage dyed with Trypan blue. Eggs spawned (A) by wild females, (B) by females fed with THA and (C) exposed to THA extracts, show analogous anomalies, characterized by abnormal dispersal of nuclear chromatin or nuclei corresponding to abnormal cell division. Incorporation of Trypan blue and their blue color indicate that they are dead embryos
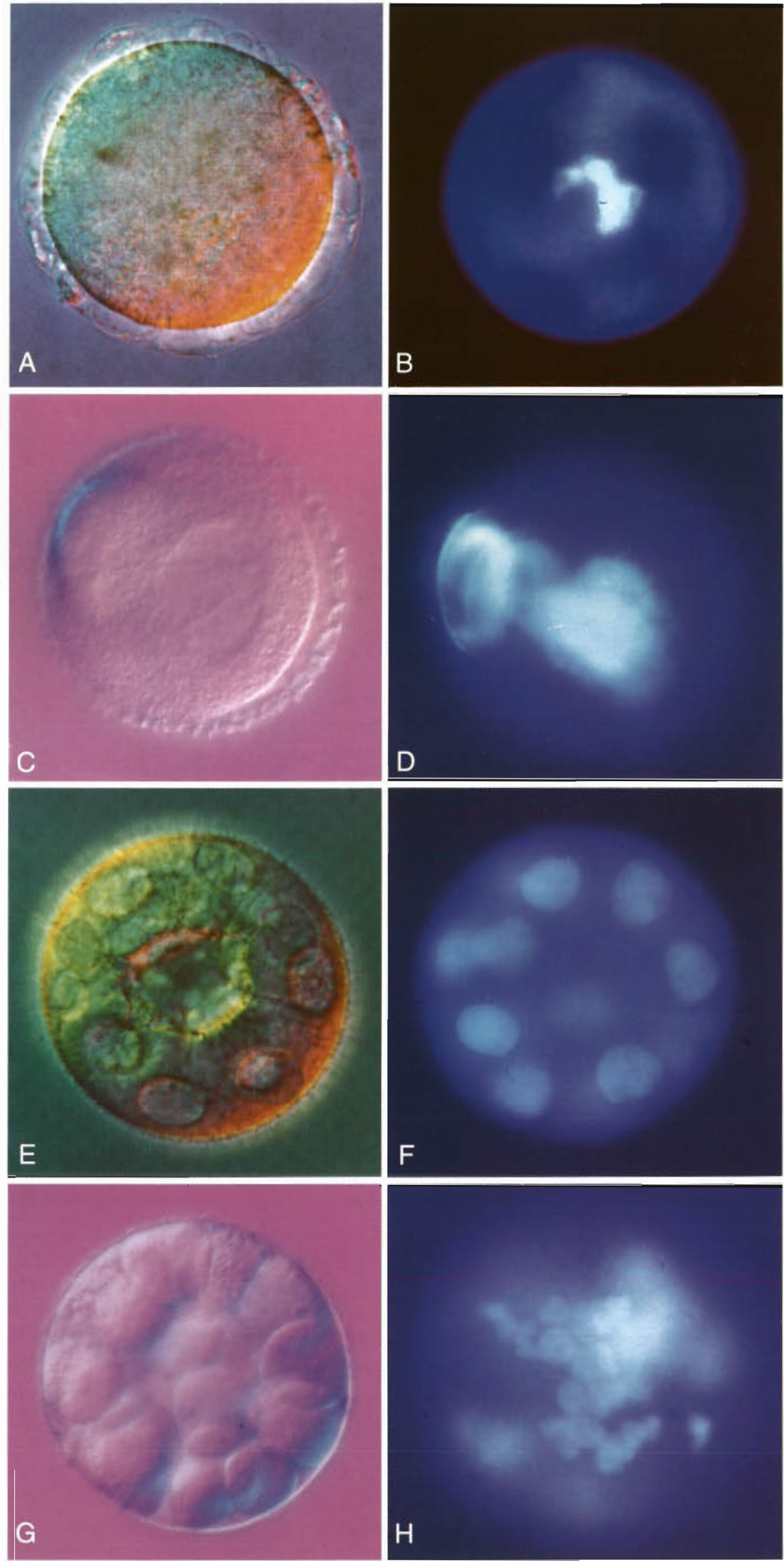
A batch of newly spawned eggs treated with THA extracts became abnormal, showing darker, opaque outer membrane, globular structures (Fig. 4C), dispersed chromatin and asymmetrical pronuclei (Fig. 4D). Eggs older than 30 min when treated with THA extracts also showed signs of abnormal cell division, characterized by the presence of globular structures (Fig. 4G) and dispersed chromatin scattered within the egg matrix (Fig. 4H), which were not observed in eggs of similar age incubated in control filtered sea water (Figs. 4E, F). Although not shown in Fig. 4, eggs incubated with concentrated PRO extracts were the same as in control.

Structural anomalies were observed in eggs spawned by wild females collected during a 1993 field survey and incubated in natural sea water (Fig. 5A), by females fed with THA (Fig. 5B), and also when spawned eggs were treated with THA extracts (Fig. 5C). These anomalies were characterized by chromatin dispersed within the cytoplasm, showing that all embryos had undergone abnormal development. Incorporation of Trypan blue by DNA in cells, and resulting blue color demonstrated that these anomalies result in embryo death 2 to $24 \mathrm{~h}$ after spawning

\section{DISCUSSION}

The cultures used in these incubations were not axenic, implying that the inhibitors might be provided either by the diatoms or by bacteria associated strictly with diatom cultures or wild populations. There is evidence, however, that inhibition originates from diatoms since copepods do not normally feed on bacteria and bacteria levels in both exponential THA and PRO cultures used for extracts were similar and extremely low.

Cell concentrations used to produce extracts necessary to block $100 \%$ cell division in eggs of Calanus helgolandicus were $10^{2}$ to $10^{3}$ times higher than naturally occurring diatom blooms. We therefore suspect that in nature, inhibitor(s) are transferred to the gonads via feeding, followed by diffusion through the gut epithelium closely apposed to the ovary (Blades-Eckelbarger 1984) and accumulation in the oocytes during vitellogenesis. There could be 2 effects: (1) inhibitory activity, or (2) inadequate nutrition. Our feeding and extract experiments with $C$. helgolandicus (Figs. 1, 2A \& 3) and with sea urchin embryos (Fig. 2B) support our first hypothesis. Hatching success with the dinoflagellate diet remained high and stable with time as compared to the lower values that decreased with time for egg viability with the diatom diet, implying that in this second case inhibitory compounds present in the diatoms were being channeled daily to the eggs (Figs. 1 \& 3 ).
Accumulation of inhibitor(s) in oocytes may also be responsible for an interruption of embryonic development in field-caught females (Fig. 5A), where blockage ranged seasonally between 2 and $70 \%$ for Calanus helgolandicus (Laabir et al. unpubl.). This range of inhibition was obtained with THA extracts representing concentrations $>10^{4}$ cells $\mathrm{ml}^{-1}$ (Fig. 2), which are close to bloom conditions. With females fed with THA, the cell concentration threshold required to reach 70 to $85 \%$ blockage (Fig. 1) was $10^{3}$ cells $\mathrm{ml}^{-1}$, which is even closer to natural bloom conditions. But in that case it accurred several days after feeding had started, whereas the lag time for inhibition was much shorter with concentrated extracts, on the order of a few minutes or hours. Although we cannot ignore the diversity of the diet of $C$. helgolandicus in the field, at times diatoms are obviously ingested (e.g. Urban et al. 1992) in quantities high enough to induce such anomalies in eggs (Fig. 5A; Laabir et al. unpubl.), and similar to those detected in eggs incubated in diatom extracts, or spawned by females fed with THA (Fig. 5B, C). Anomalies were also observed in Temora stylifera fed 4 different diatom diets (Ianora et al. unpubl.), as well as in naturally occurring Centopages typicus eggs (lanora et al. 1992, their Fig. 3F), even though the cause was unknown at that time.

In nature, diatoms, unlike other toxic phytoplankters, are not ephemeral. In aquaculture and laboratory experiments they have been used as a food source for zooplankton growth (e.g. Vidal 1980). The physiological response reported in our experiments does not contradict this view. At this point, it is necessary to reexamine our understanding of the role of diatoms in the biology of copepods (see review by Kleppel 1993). On the one hand, they seem to provide the necessary nutrients for somatic growth (e.g. Vidal 1980, Saiz et al. 1993), and, on the other, some of them contain inhibitor(s) detrimental to embryonic growth (i.e. blockage of cell mitosis and embryonic development: Figs. 1 to 5). These 2 functions are independent.

The chemistry of the food in terms of proteins, carbohydrates, lipids, vitamins, etc. has been demonstrated to affect egg production. Food 'quality' in this sense has been investigated in Temora stylifera, and our results indicate that, at saturated food levels, there are no major differences in total egg production between THA and PRO (Ianora \& Poulet 1993). We suspect that egg viability is also affected by the presence of inhibitor(s) in the diet (in diatoms including unknown compound which act as anti-mitotic agents, such as okadaic acid; see review by Cohen et al. 1990). Experiments are being conducted to chemically identify this inhibitor, with screening of the algae in order to establish whether or not this inhibition is restricted to the 4 species of diatoms already tested with $T$. stylifera 
(Ianora et al. unpubl.). The results of this study on Calanus helgolandicus and the previous observations on T. stylifera (Ianora \& Poulet 1993, Ianora et al. unpubl.), indicate that the inhibition of embryonic development in copepods by diatoms may have evolved to reduce the reproductive effort, and therefore densities, of the grazers. Such response has a strong bearing in natural situations since the induction time for inhibition is on the order of 2 to $3 \mathrm{~d}$ (Fig. 1; Ianora \& Poulet unpubl.), whereas diatom blooms generally last days to weeks. Copepods may reduce the effects by shifting their diet to non-diatom food items belonging to the microbial food web (Urban et al. 1992). Alternatively, they may synchronize egg production cycles in time with non-diatom blooms, as shown in T. stylifera (Ianora et al. 1989, Ianora \& Poulet 1993), and in space with relation to patchy food microdistribution (Saiz et al. 1993). The 4 species of copepods (C. helgolandicus: Figs. 1, 2 \& 3; T. stylifera, Acartia clausi and Centropages typicus: Ianora \& Poulet 1993, Ianora et al. unpubl., Miralto et al. unpubl.) fed the same strains of Thalassiosira rotula, all were similarly inhibited. Assuming that copepods maximize fecundity when food is not limiting, irrespective of the diet (e.g. Uye 1981, Plourde \& Runge 1993), the final outcome of egg production (i.e. hatching of nauplii and favorable recruitment) will probably be reduced with a diatom diet (see also lanora \& Poulet 1993, their Fig. 3 and Table 1). Therefore, we predict that any modification in phytoplankton diversity, shifting from diatoms to non-diatoms or vice versa - due to normal seasonal variations (Urban et al. 1992, Ianora \& Poulet 1993) and water conditions, 'global change' or anthropogenic nutrient enrichment of the marine environment (Larsson et al. 1985) - will ultimately affect secondary production by changing copepod recruitment rates.

Acknowledgements. This work was supported by CNRS-CNR grants MDRCI Nos. 29 \& 30, and by both Roscoff and Naples Marine Stations. We thank F. Esposito, R. Faveris, $O$ Leborgne and $\mathrm{G}$. Gargiulo for their technical assistance, and Drs R. Williams and M. Montresor for helpful discussions and for providing the algae. Anonymous referees are sincerely acknowledged for their critical advice and suggestions.

\section{LITERATURE CITED}

Blades-Eckelbarger, P. 1. (1984). Aspects of internal anatomy and reproduction in the copepoda. Syllogeus 58:26-50

Cohen, P., Holmes, C. F. B., Tsukitani, Y. (1990). Okadaic acid: a new probe for the study of cellular regulation. TIBS 15: 98-102

DeMott, W. R., Zhang, Q. X., Carmichael, W. W. (1991). Effects of toxic cyanobacteria and purified toxins on the survival and feeding of a copepod and three species of Daphnia. Limnol. Oceanogr. 36: 1346-1357
Douglas, D. J., Bates, S. S. (1991). Production of domoic acid, a neurotoxic amino acid, by an axenic culture of the marine diatom Nitzchia pungens f. multiseries Hasle. Can. J. Fish. Aquat. Sci. 49: 85-90

Huntley, M. E., Ciminiella, P., Lopez, M. D. G. (1987). Importance of food quality in determining development and survival of Calanus pacificus (Copepoda: Calanoida). Mar. Biol. 95: 103-113

lanora, A., Mazzocchi, M. G., Grottoli, R. (1992). Seasonal fluctuations in fecundity and hatching success in the planktonic copepod Centropages typicus. J. Plankton Res. 14: $1483-1494$

Ianora, A., Poulet, S. A. (1993). Egg viability in the copepod Temora stylifera. Limnol. Oceanogr. 38: 1615-1626

Ianora, A., Poulet, S. A., Miralto, A. (1994). A comparative study of the inhibitory effects of diatoms on the reproductive biology of the copepod Temora stylifera. Mar. Biol. (in press)

Ianora, A., Scotto di Carlo, B., Mascellaro, P. (1989). The reproductive biology of the planktonic copepod Temora stylifera. Mar. Biol. 101: 187-194

Imada, N., Kobayashi, K., Tahara, K., Oshima, Y. (1991). Production of an autoinhibitor by Skeletonema costatum and its effect on the growth of other phytoplankton. Nippon Suisan Gakk. 57: 2285-2290

Kiørboe, T., Mohlenberg, F., Tiselius, P. (1988). Propagation of planktonic copepods: production and mortality of eggs. Hydrobiologia 167/168: 219-225

Kirk, K. L., Gilbert, J. J. (1992). Variation in herbivorous response to chemical defenses: zooplankton foraging on toxic cyanobacteria. Ecology 73: 2208-2217

Kleppel, G. S., Holliday, D. V., Pieper, R. E. (1991). Trophic interactions between copepods and microplankton: a question about the role of diatoms. Limnol. Oceanogr. 36 $172-178$

Kleppel, G. S. (1993). On the diets of calanoid copepods. Mar Ecol. Prog. Ser. 99: 183-195

Larsson, U., Elmgren, R., Wulff, F. (1985). Eutrophication and the Baltic Sea: causes and consequences. Ambio 14: 9-14

Marshall, I. A., Orr, A. P. (1972). The biology of a marine copepod. Springer-Verlag, Berlin

Meijer, L., Azzi, L., Wang, J. Y J. (1991). Cyclin B targets p $34^{\mathrm{cdc} 2}$ for tyrosine phosphorylation. The EMBO J. 10 1545-1554

Pesando, D., Graillet, C., Braekman, J. C., Dubreuil, A., Girard, J. P., Puiseux-Dao, S. (1990). The use of sea urchin eggs as a model to investigate the effects of crassolide, a diterpene isolated from a soft coral. In: Reinhardt, C. A., Blaauboer, B. J. (eds.) Proceedings of the Sixth International Workshop on In Vitro Toxicology, Vol. 5, No. 5-6. Pergamon Press, Tarritown, p. 395-401

Plourde, S., Runge, J. A. (1993). Reproduction of the copepod Calanus finmarchicus in the lower St. Lawrence Estuary: relation to the cycle of phytoplankton production and evidence for a Calanus pump. Mar. Ecol. Prog. Ser. 102: $217-227$

Saiz, E., Tiselius, P., Jonsson, P. R., Verity, P., Paffenhöfer, G.-A. (1993). Experimental records of the effects of food patchiness and predation on egg production of Acartia clausi. Limnol. Oceanogr. 38: 280-289

Scherrer, B. (1984). Biostatistique. G. Morin, Québec

Scotto di Carlo, B., Tomas, C. R., Ianora, A., Marino, D., Mazzocchi, M. G., Modigh, M., Montresor, M., Petrillo, L., Ribera d'Alcala, M., Saggiomo, V., Zingone, A. (1985) Uno studio integrato dell'ecosistema pelagico costiero del golfo di Napoli. Nova Thalassia 7: 99-128

Siegel, S. (1956). Nonparametric statistics for the behavioral 
sciences. McGraw-Hill Book Co., New York

Smayda, T. J. (1991). Global epidemic of noxıous phytoplankton blooms and food chain consequences in large ecosystems. In: Sherman, K., Alexander, L. M., Gold, B. D. (eds.) Food chains, yields, models, and management of large marine ecosystems. Westview Press, Boulder, p. $275-307$

Urban, J. L., McKenzie, C. H., Deibel, D. (1992). Seasonal differences in the contents of Oikopleura vanhoeffeni and Calanus finmarchicus faecal pellets: illustrations of zooplankton food web shifts in coastal Newfoundland waters. Mar. Ecol. Prog. Ser. 84: 255-264

This article was submitted to the editor
Uye, S. 1. (1981). Fecundity studies of neritic calanoid copepods Acartia clausi Giesbrecht and A steueri Smirnov: a simple empirical model of daily egg production. J. exp. mar. Biol. Ecol. 50: 255-271

Verity, P. G., Smayda, T. J. (1989). Nutritional value of Phaeocystis pouchetii (Prymnesiophyceae) and other phytoplankton for Acartia spp. (Copepoda): ingestion, egg production and growth of nauplii. Mar. Biol. 100: 161-171

Vidal, J. (1980). Physioecology of zooplankton. II. Effects of phytoplankton concentration, temperature and body size on the development and molting rates of Calanus pacificus and Pseudocalanus. Mar. Biol. 56: 134-146

Manuscript first received: February 8, 1994

Revised version accepted: June 9, 1994 